\title{
EEG Correlations during a Working Memory Task with Emotional Stimuli in Girls with Post-Traumatic Stress Disorder Secondary to Sexual Abuse
}

\author{
Araceli Sanz-Martin, Ivette Calderón-Zepeda \\ Instituto de Neurociencias, Universidad de Guadalajara, Guadalajara, Jalisco, México \\ Email: aracelisanz@yahoo.com
}

How to cite this paper: Sanz-Martin, A. and Calderón-Zepeda, I. (2016) EEG Correlations during a Working Memory Task with Emotional Stimuli in Girls with Post-Traumatic Stress Disorder Secondary to Sexual Abuse. Journal of Behavioral and Brain Science, 6 , 509-529.

http://dx.doi.org/10.4236/jbbs.2016.612046

Received: August 25, 2016

Accepted: November 1, 2016

Published: November 4, 2016

Copyright (c) 2016 by authors and Scientific Research Publishing Inc. This work is licensed under the Creative Commons Attribution International License (CC BY 4.0).

http://creativecommons.org/licenses/by/4.0/

\begin{abstract}
Survivors of Child Sexual Abuse (CSA) can develop Post-Traumatic Stress Disorder (PTSD), alterations in the prefrontal cortex, changes in electroencephalographic (EEG) activity, and lower performance on working memory tasks. The aim of this study was to characterize brain electrical correlations in girls with PTSD secondary to CSA during a working memory task based on recognizing emotional facial stimuli. Girls aged 8 - 16 years old were evaluated: 12 with PTSD secondary to CSA, and 12 healthy girls with no history of abuse. EEG activity during a working memory task with emotional stimuli was recorded, and the inter- and intra-hemispheric correlations that assessed the functional connectivity among different cortical regions were analyzed. The PTSD group showed lower performance than controls on the working memory task while watching happy faces, while the EEG of this group showed greater intrahemispheric correlation among frontal areas and between frontal and posterior cortical regions. Also, the PTSD group had lower interhemispheric correlations between posterior temporal areas. The higher intrahemispheric correlation in the PTSD group could indicate that those girls used more brain areas when performing the task, likely because it required greater effort. The lower inter-posterior temporal correlation could be attributed to a reduction of the corpus callosum.
\end{abstract}

\section{Keywords}

Child Sexual Abuse, PTSD, Working Memory, Emotional Stimuli, EEG Correlation, Early Stress

\section{Introduction}

Survivors of child sexual maltreatment experience a lifelong increase in the incidence of 
psychopathologies [1], such as depression, anxiety, substance abuse, and Post-Traumatic Stress Disorder (PTSD) [2]. Also, they are often hyper-responsive to both angry [3]] [4] and fearful faces [5], and may show deficits in working memory [6]. Considering that memory can be influenced by the emotional content of the stimuli that are to be recalled [7], understanding the relationship between working memory and emotional mechanisms linked to stress suffered early in life requires developing interventions designed to diminish the adverse effects of child maltreatment. In this regard, Cromheeke, Herpoel and Mueller [8] compared the impact of distracting emotional information on working memory performance in women with a history of sexual and physical abuse during childhood/adolescence, individuals reporting non-abuse-related childhood stress, and women without childhood stress. They found that working memory accuracy for positive vs. neutral incidental emotional stimuli was reduced in the women who reported a history of abuse compared to both control groups.

Survivors of child maltreatment may also show physiological changes, such as abnormal responses of the Hypothalamic-Pituitary-Adrenal (HPA) axis [9], lower volume of the brain structures related to memory and emotional processing, including the prefrontal cortex, the corpus callosum and the hippocampus [10], as well as increased cerebral blood flow in the anterior prefrontal cortex, the posterior cingulate [11] and the amygdala, during recall of threatening events [12]. Electroencephalogram (EEG) shows changes in the functional connectivity among several brain regions and this phenomenon can be assessed by EEG coherence (coh) and correlation (r) [13] [14]. These are mathematical calculations that evaluate the degree of similarity between two EEG signals [15]. In particular, children and adolescents with a history of child maltreatment have been shown to present an increase in left intrahemispheric coherence and a decrease in frontal interhemispheric coherence while at rest [16] [17].

EEG has also been used to measure the functional brain connectivity that underlies working memory, showing that there is a link between frontal and posterior cortical regions in this process (especially in the temporal and parietal lobes) in the theta and alpha bands [18] [19] [20]. These electrophysiological findings support Baddeley's [21] model, which considers that working memory is a system integrated by an attentional control system (or executive system) located in the dorsolateral prefrontal cortex and other slave buffers found in posterior cortical areas. The executive system organizes and supervises the information stored in the slave systems such that coordination and synchronized processing among prefrontal and posterior cortical regions are fundamental. However, no EEG studies have yet examined the cortical connectivity underlying working memory in survivors of child maltreatment.

On the other hand, due to the frequent co-occurrence of multiple stressors, most of the aforementioned studies have included individuals who experienced different types of stress early in life. In contrast, only a few differentiated among the types of stressors [10] [22].

In light of the evidence presented above, this research was conducted to characterize EEG correlations during performance of a working memory task based on emotional stimuli in children and adolescents with PTSD secondary to Child Sexual Abuse (CSA). 
We hypothesized that the PTSD group would show lower performance on the working memory task with happy faces compared to the healthy girls without abuse. Also, we predicted that the PTSD group would show different EEG correlations among prefrontal and posterior cortical areas from those detected in controls, especially while observing happy faces.

\section{Method}

\subsection{Participants}

Twenty-four girls aged 8 - 16 years old were evaluated from January 2012 to January 2013: 12 with PTSD secondary to child sexual abuse (the PTSD group), and 12 healthy girls with no history of abuse (control group). In order to control for socioeconomic status and the stress of being away from family, both groups were recruited from foster homes where they had lived for at least 6 months prior to evaluation. All participants had entered the foster homes after the age of five years. The girls with PTSD were placed in the homes after a legal process because of the sexual abuse they had suffered in their families, while the control subjects entered because their parents or guardians had low income and so were unable to provide the girls with proper care. The PTSD participants rarely received visits from their relatives, while those in control group spent weekends and holidays with their families.

We confirmed that the PTSD participants presented histories of intra-familiar CSA by reviewing files held at the foster homes and through semi-structured interviews. Abuse had been perpetrated by the father, stepfather or an uncle. In 12 cases abuse was characterized as "fondling", while the other two girls had been raped. According to the files and our semi-structured interviews, control participants had no history of either sexual or severe physical abuse.

All participants had normal IQs according to the brief form of the WISC-IV [23], and were regular students with no reports of behavioral problems. All were healthy, right-handed, and had no prior history of neurological disorders, learning disabilities, drug abuse (personal or by the mother), chronic illness or attention deficit disorder, according to the DSM-5 criteria [24]. Subjects in control group were matched with those in PTSD with respect to age, handedness, socioeconomic status, IQ scores and school grade.

To select participants, we interviewed each girl and her parents or advisors, and applied the WISC-IV, child abuse screening tool (ICAST-C) [25] and the child PTSD symptom scale (CPSS) [26]. The latter allowed us to determine the presence and intensity of PTSD and the kind of abuse experienced by participants according to DSM-IV criteria, and yields a PTSD total score as well as scores on the re-experiencing, avoidance and hyper arousal subscales. In addition, the children's depression inventory (CDI) [27] was applied to determine the presence of depressive symptoms.

All procedures involved in this research were approved by the Ethics Committee of the Institute of Neuroscience in accordance with the ethical standards laid down in the 
1964 Helsinki Declaration. All participants and their parents or guardians gave their informed consent prior to inclusion in the study.

\subsection{Working Memory Task}

During the task, 120 black-and-white pictures of adult men and women with happy, angry, fearful, sad or neutral expressions were used. Each photograph was presented twice. The working memory task consisted of 60 trials in which three pictures with different expressions were presented one-by-one. The participant had to try to remember the order of appearance of the emotional expressions in each series of three photos because after a tone a fourth picture appeared (the target stimulus) showing the face of another person with one of the three previous expressions. The order of appearance of the stimuli to be recalled $(1,2$ or 3$)$ was counterbalanced. There were 12 target stimuli for each emotional content (i.e., happy, angry, fearful, sad and neutral). Using the 1, 2 or 3 keys of a numeric computer keypad the participant had to indicate which of the three original photographs had the expression that coincided with the fourth (Figure 1). Each stimulus remained on the screen for 1 second and the inter-stimulus interval was 3 seconds. After the target stimulus appeared, the inter-stimulus interval lasted 4 seconds. To avoid fatigue, the task was divided into three series of 20 trials each. The number of correct responses and the response times were recorded for each trial.

\subsection{Pairing Task}

The objective of this task was to determine whether the participants were able to distinguish the different facial expressions. In each trial, four photographs with emotional expressions of sadness, anger, fear, happiness and neutral were presented on a screen as follows: one photo appeared at the top of the screen and the other three at the bottom. One of the photos below had the same expression (but not the same person) as in the photo above. Using the 1, 2 or 3 keys of the numeric computer keypad the participant had to indicate which of the three lower photos had the expression that coincided with the one above. In this task, the photos remained on the screen until the participant responded, or 7 seconds had elapsed. The number of correct responses was counted.

\subsection{EEG Recording and Analysis}

EEGs were recorded in a shielded, dimly-lit room for three minutes at rest and during performance of the working memory task. The recording sites were located in the frontal (F3, F4, F7, F8), temporal (T3, T4, T5, T6) and parietal (P3, P4) cortical areas according to the 10 - 20 International System. EEGs were collected using a Neuroscan cap with sintered silver chloride electrodes referenced to linked earlobes to avoid distortions due to asymmetrical impedances at A1 and A2 [28]. Impedances were maintained below 10 Kohms. Electrodes were also placed on the top and bottom edges of the eyes and the left wrist to control for artifacts caused by eye movements or heart beat.

EEG data were recorded using a Neuroscan NuAmps digital amplifier with filters set at 1 and $50 \mathrm{~Hz}$, digitized at a sampling rate of $500 \mathrm{~Hz}$, and stored on a PC by Scan 4.3 


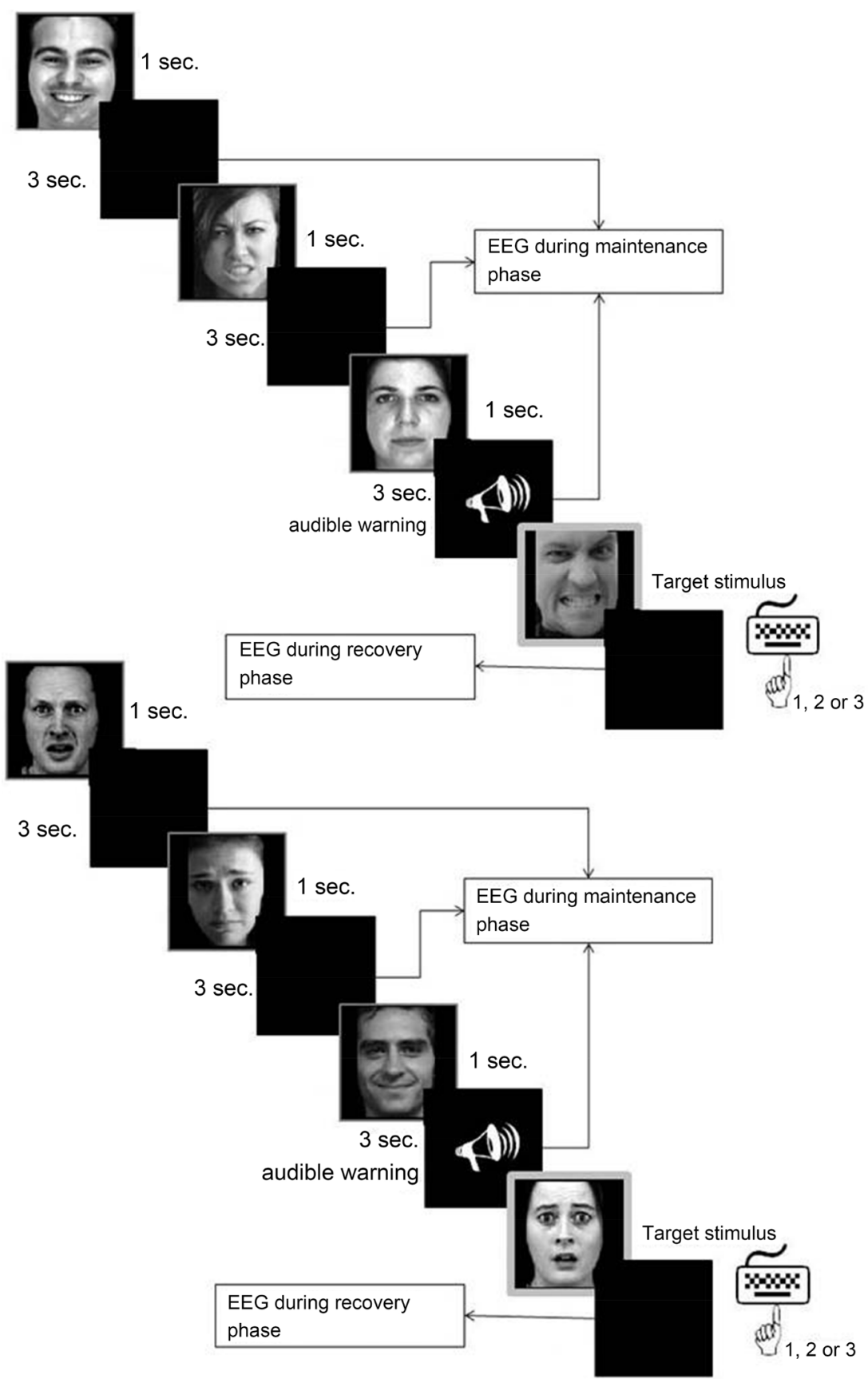

Figure 1. Working memory task. During the maintenance phase, three faces with different emotional or neutral content were shown on the screen one-by-one; the participant had to remember the order of these expressions, because after a tone (warning), a fourth face (the target stimulus) of another person with an expression that matched one of the previous three appeared. During the recovery phase, the participant had to indicate which one of the three original photos $(1,2$ or 3 ) showed the same expression as the target stimulus (\#2 and \#1 in the examples). Each stimulus remained on the screen for 1 second and the inter-stimulus interval was $3 \mathrm{sec}$, except after the target stimulus when 4 seconds were allowed. For EEG analysis, only segments recorded during the inter-stimulus intervals were analyzed, either when the participant had to maintain the information in working memory (maintenance phase), or when she had to retrieve the stored information and give a response (recovery phase). 
Acquisition Software. Using this program, 1-second epochs were obtained and then separated into the maintenance and recovery phases. Also, in each phase (maintenance, recovery), epochs were separated according to the neutral or emotional content of the photos (happy, anger, fear, sadness). As Figure 1 shown, EEG epochs that integrated the maintenance and recovery phases were obtained from the inter-stimulus intervals.

The EEGs corresponding to each phase and content (emotional or neutral) were examined manually using the CHECASEN computer program [29]. All epochs contaminated by noise were removed to ensure that all signals analyzed were artifact-free. Later, these EEGs were analyzed by the EEG Magic software [30] that initially calculated the Fast Fourier Transform (FFT) to seven frequency bands: delta $(1-3 \mathrm{~Hz})$, theta (4 - $7 \mathrm{~Hz})$, alpha1 $(8-10 \mathrm{~Hz})$, alpha2 $(11-13 \mathrm{~Hz})$, beta1 $(14-19 \mathrm{~Hz})$, beta2 $(20-30 \mathrm{~Hz})$ and gamma $(31-50 \mathrm{~Hz})$. The correlation spectrum $(\mathrm{r})$ was then calculated from the autospectra and the cross-spectrum of the signals to provide values between -1 and +1 . Correlation spectra at 0 delay for each subject and condition were obtained for each frequency band using amplitude values by means of Pearson product-moment coefficients to obtain intrahemispheric correlations (intra-r) between derivations in the left (F3-F7, F3-T3, F3-T5, F3-P3) and right (F4-F8, F4-T4, F4-T6, F4-P4) hemispheres. The interhemispheric correlations (inter-r) were also obtained; that is, the correlation between homologous left and right cortical areas (F3-F4, F7-F8, T3-T4, T5-T6, P3-P4). The correlation function $(r)$ at each given frequency $\mathrm{x}$ is defined by:

$$
r(x)=C A B(x) / C A A C B B
$$

where $C$ is the cross-covariance between signals $A$ and $B ; C A A$ is the auto-covariance of signal $A$; and $C B B$ is the auto-covariance of signal $B$. The correlation is sensitive to both the phase and polarity of the signal, regardless of amplitude [31].

Finally, in order to approximate to a normal distribution, the correlation values were transformed into $\mathrm{Z}$ scores before beginning statistical analysis.

\subsection{Statistical Analysis}

To test for differences in performance between groups and type of stimulus on both the pairing and working memory tasks, ANOVAs for correlated groups were performed for each set of test data. Post-hoc comparisons were conducted to determine where differences occurred $(\mathrm{p}<0.05)$. The same kinds of ANOVAs were applied to the EEGs for each condition (maintenance, recovery), derivation and band. To compare the EEGs between groups while at rest, a T Student analysis for correlated groups was made for each derivation and frequency band.

Finally, in the statistical analysis of the EEGs, the p-values were adjusted by applying the Bonferroni method to correct the multiple comparisons and so avoid Type I error. The new level of significance was 0.0005 .

\section{Results}

\subsection{Characteristics of Participants}

None of the participants in control group presented significant symptoms of PTSD, and 
no PTSD subjects showed significant symptoms of depression. Only one girl in control group had mild symptoms of this disorder. There were significant between-group differences in the CPSS test scores $(\mathrm{p}<0.000)$, but there were not in terms of age, IQ and CDI scores (Table 1).

\subsection{Behavioral Performance on the Tasks}

No between-group differences were observed on the working memory task $\left(\mathrm{F}_{1,11}=\right.$ $1.335, \mathrm{p}=0.272)$, or emotion-group interaction $\left(\mathrm{F}_{4,44}=0.801, \mathrm{p}=0.531\right)$ in the number

Table 1. Mean and standard deviation (SD) of the characteristics of the control and posttraumatic stress disorder (PTSD) groups. The significances $(\mathrm{P})$ in the T student test performed to determine the differences between groups are included.

\begin{tabular}{lccccc} 
& \multicolumn{2}{c}{ Control } & \multicolumn{2}{c}{ PTSD } & \multirow{2}{*}{ P } \\
\cline { 2 - 5 } & Mean & SD & Mean & SD & \\
\cline { 2 - 5 } Age & 12.1 & 2.3 & 11.9 & 2.5 & 0.593 \\
Raw CPSS score & 4.7 & 5.1 & 33.33 & 4.7 & $0.000^{*}$ \\
Raw CDI score & 10.9 & 4.77 & 9.1 & 5.56 & 0.896 \\
Estimated IQ & 90 & 6 & 89.83 & 8.7 & 0.415 \\
abuse duration (months) & & & 22.9 & 17.89 & \\
f onset of sexual abuse & & & 8.1 & 2.4 & \\
\hline
\end{tabular}

*Significant difference between PTSD and control groups.

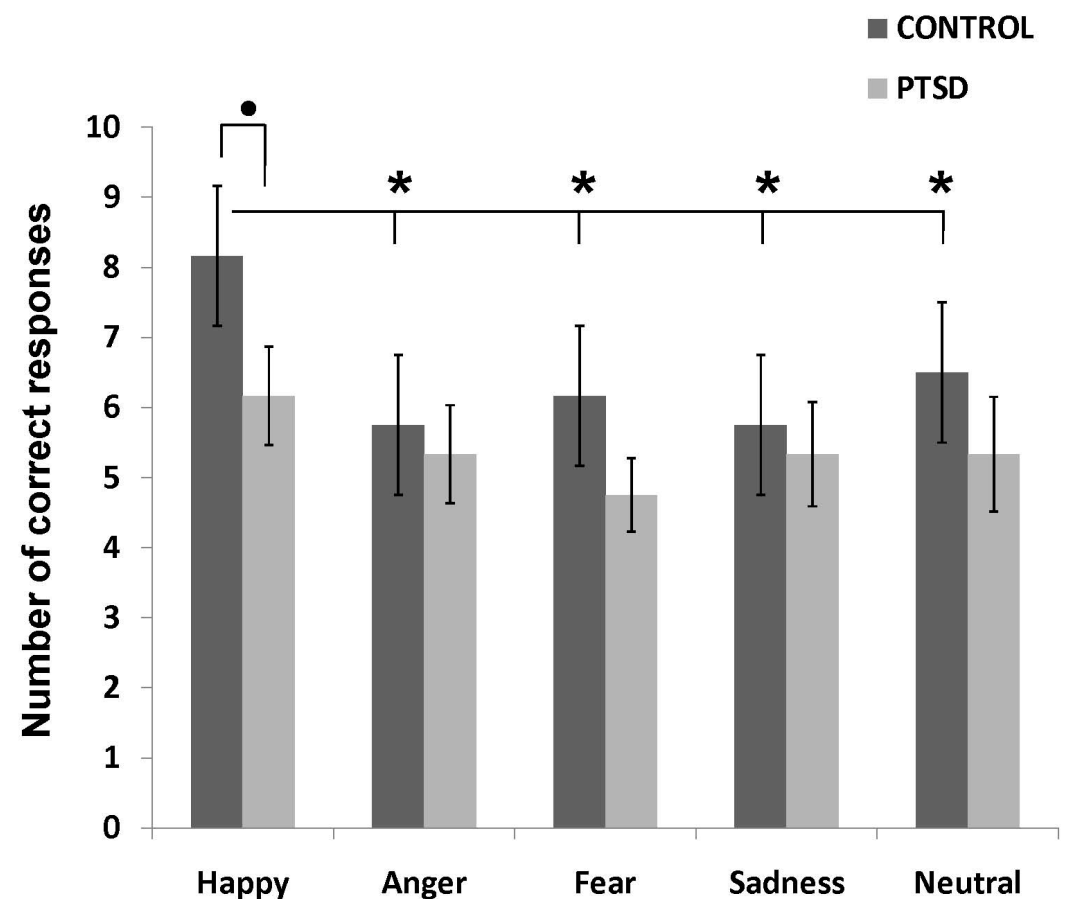

Figure 2. Number of correct responses (mean \pm 2 standard error) for each kind of stimulus on the working memory task in the control and post-traumatic stress disorder (PTSD) groups. ${ }^{*} \mathrm{p}<$ $0.001, \bullet \mathrm{p}<0.05$. 
of correct responses, but there were significant differences among the types of stimuli $\left(\mathrm{F}_{4,44}=5.061, \mathrm{p}=0.002\right)$. As Figure 2 shown, differences among the emotional stimuli occurred only in control group, so although the ANOVA showed no significant interaction, we decided to conduct a post-hoc analysis which revealed that control group achieved more correct responses when shown the happy stimulus than the other stimuli. Also, PTSD participants had a lower number of correct responses than controls only when observing happy faces.

With regard to reaction times, there were no significant differences between the groups $\left(\mathrm{F}_{1,11}=1.089, \mathrm{p}=0.319\right)$ or for the type of stimulus $\left(\mathrm{F}_{4,44}=1.867, \mathrm{p}=0.133\right)$, and no interactions between these variables $\left(\mathrm{F}_{4,44}=1.311, \mathrm{p}=0.281\right)$.

There were no significant between-group differences on the pairing task $\left(\mathrm{F}_{1,11}=0.546\right.$, $\mathrm{p}=0.476)$, or interactions between these variables $\left(\mathrm{F}_{4,44}=0.789, \mathrm{p}=0.539\right)$, but there were significant differences for the types of stimuli $\left(\mathrm{F}_{4,44}=11.313, \mathrm{p}=0.000\right)$, as participants achieved more correct responses for the happy stimulus than the neutral one.

\subsection{EEG Correlations}

\subsubsection{Resting}

The PTSD group had higher r-intra than controls between the left frontal and parietal areas (F3-P3) in the alpha2 band ( $\mathrm{p}=0.0496)$, and between the right frontal and parietal regions ( $\mathrm{F} 4-\mathrm{P} 4)$ in theta $(\mathrm{p}=0.03)$, alpha1 $(\mathrm{p}=0.003)$, alpha2 $(\mathrm{p}=0.03)$ and beta1 $(\mathrm{p}$ $=0.039)$. Also, PTSD group showed a greater inter-parietal correlation (P3-P4) in the alpha1 band $(\mathrm{p}=0.024)$. However, after applying Bonferroni correction for multiple comparisons none of these results remained significant.

\subsubsection{Maintenance phase}

PTSD group had higher r-intra than control group between the left frontal areas (F3-F7) and bilaterally between the frontal-temporal (F3-T3, F3-T5, F4-T6) and frontal-parietal (F3-P3, F4-P4) regions in the bands listed in Table 2. Control group only showed higher r-intra between the left frontal-posterior temporal regions (F3-T5) in the beta2 band (Figure 3). As Table 2 shown, after Bonferroni correction, the comparisons that did not reach significance were: F3-F7 in delta and alpha2, F3-T5 in delta and Beta2, F3-T5 in alpha2 and beta2, F4-T6 in theta, and F4-P3 in theta.

There were no significant differences among type of stimulus or interactions among variables.

PTSD group presented lower inter-r than control group between the anterior temporal regions (T3-T4) in alpha1, alpha2, beta1 and beta2, as well as between posterior temporal regions (T5-T6) in all bands (Table 2). The exception was the gamma band between T3-T4, where this group had a higher correlation. In addition, PTSD had higher inter-r between the inferior frontal regions (F7-F8) in beta1 and gamma, as well as between the parietal areas (P3-P4), though exclusively in alpha1 (Figure 4, Table 2). After Bonferroni correction, the comparisons at F7-F8 in beta1, T3-T4 in alpha1 and beta2, T5-T6 in delta and P3-P4 alpha1 did not reach the level of significance. There were no significant differences among type of stimuli or interactions among variables. 
Table 2. ANOVAS of the inter- and intrahemispheric EEG correlations during the maintenance phase. F values (free grades) and the significance ( $p$ ) of the pair of derivations and bands where there were significant differences between the control and post-traumatic stress disorder groups.

\begin{tabular}{|c|c|c|c|c|}
\hline & Pairs of Derivations & Bands & $\mathrm{F} 1,99$ & $\mathrm{p}<$ \\
\hline \multirow[t]{27}{*}{ Intrahemispheric correlation } & \multirow[t]{5}{*}{ F3-F7 } & Delta & 6.67 & 0.01 \\
\hline & & Alpha2 & 9.55 & 0.002 \\
\hline & & Beta1 & 30.95 & $0^{\star}$ \\
\hline & & Beta2 & 44.85 & $0^{*}$ \\
\hline & & Gamma & 41.32 & $0^{*}$ \\
\hline & \multirow[t]{3}{*}{ F3-T3 } & Delta & 10.59 & 0.001 \\
\hline & & Beta2 & 12.11 & 0.001 \\
\hline & & Gamma & 15.76 & $0^{\star}$ \\
\hline & \multirow[t]{3}{*}{ F3-T5 } & Alpha1 & 21.38 & $0^{*}$ \\
\hline & & Alpha2 & 11.9 & 0.001 \\
\hline & & Beta2 & 9.3 & 0.003 \\
\hline & \multirow[t]{4}{*}{$\mathrm{F} 4-\mathrm{T} 6$} & Delta & 13.34 & $0^{\star}$ \\
\hline & & Theta & 8.7 & 0.004 \\
\hline & & Alpha1 & 28.63 & $0^{\star}$ \\
\hline & & Alpha2 & 24.01 & $0^{*}$ \\
\hline & \multirow[t]{5}{*}{ F3-P3 } & Delta & 26.76 & $0^{*}$ \\
\hline & & Theta & 10.23 & 0.002 \\
\hline & & Alpha1 & 44.1 & $0^{*}$ \\
\hline & & Alpha2 & 39.72 & $0^{*}$ \\
\hline & & Betal & 12.76 & $0^{*}$ \\
\hline & \multirow[t]{7}{*}{$\mathrm{F} 4-\mathrm{P} 4$} & Delta & 55.47 & $0^{*}$ \\
\hline & & Theta & 50.35 & $0^{\star}$ \\
\hline & & Alpha1 & 79.34 & $0^{*}$ \\
\hline & & Alpha2 & 60 & $0^{\star}$ \\
\hline & & Betal & 73.61 & $0^{*}$ \\
\hline & & Beta2 & 44.59 & $0^{*}$ \\
\hline & & Gamma & 21.22 & $0^{*}$ \\
\hline \multirow[t]{15}{*}{ Interhemispheric correlation } & & Beta1 & 6.15 & 0.01 \\
\hline & \multirow[t]{2}{*}{ F7-F8 } & Gamma & 12.98 & $0^{*}$ \\
\hline & & Alpha1 & 9.91 & 0.002 \\
\hline & \multirow[t]{4}{*}{$\mathrm{T} 3-\mathrm{T} 4$} & Alpha2 & 13.85 & $0^{*}$ \\
\hline & & Beta1 & 15.32 & $0^{*}$ \\
\hline & & Beta2 & 11.66 & 0.001 \\
\hline & & Gamma & 22.56 & $0^{*}$ \\
\hline & \multirow[t]{7}{*}{ T5-T6 } & Delta & 6.78 & 0.01 \\
\hline & & Theta & 27.01 & $0^{*}$ \\
\hline & & Alpha1 & 18.76 & $0^{*}$ \\
\hline & & Alpha2 & 49.74 & $0^{*}$ \\
\hline & & Betal & 82.63 & $0^{*}$ \\
\hline & & Beta2 & 39.15 & $0^{\star}$ \\
\hline & & Gamma & 36.98 & $0^{*}$ \\
\hline & P3-P4 & Alpha1 & 6.84 & 0.01 \\
\hline
\end{tabular}

${ }^{\star}$ Significant after Bonferroni correction $(\mathrm{p}<0.0005)$. 


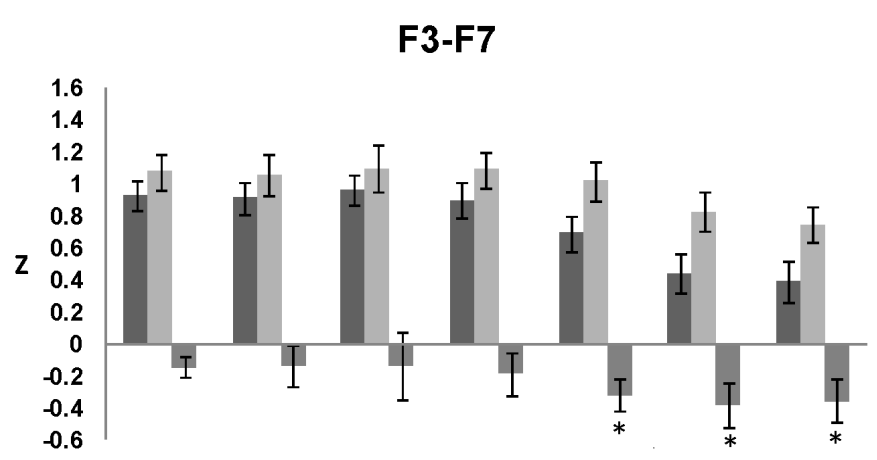

F3-T5

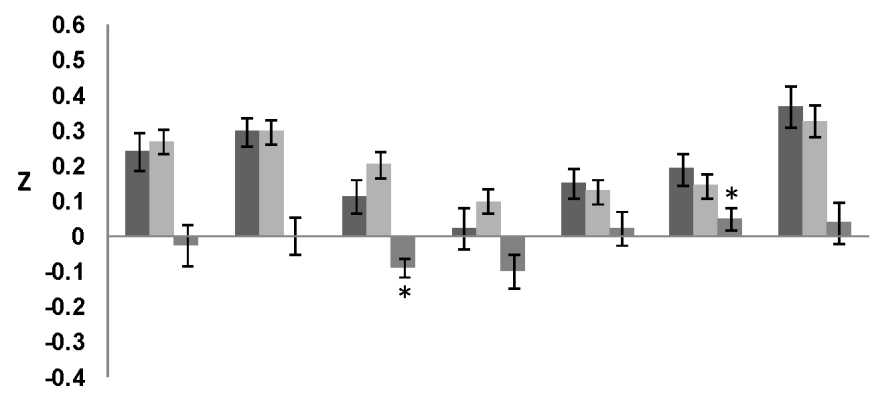

F3-P3

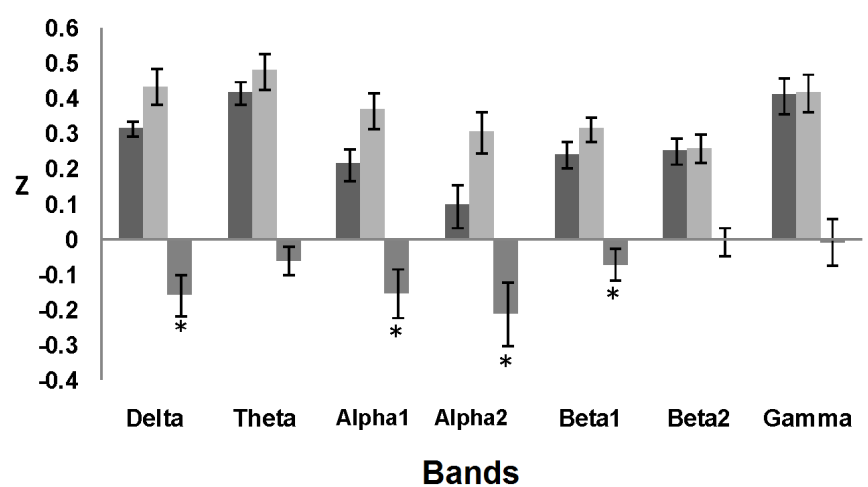

F3-T3

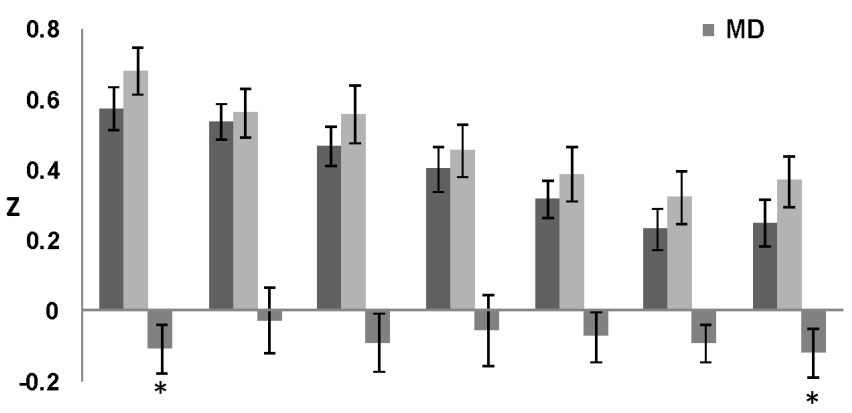

F4-T6

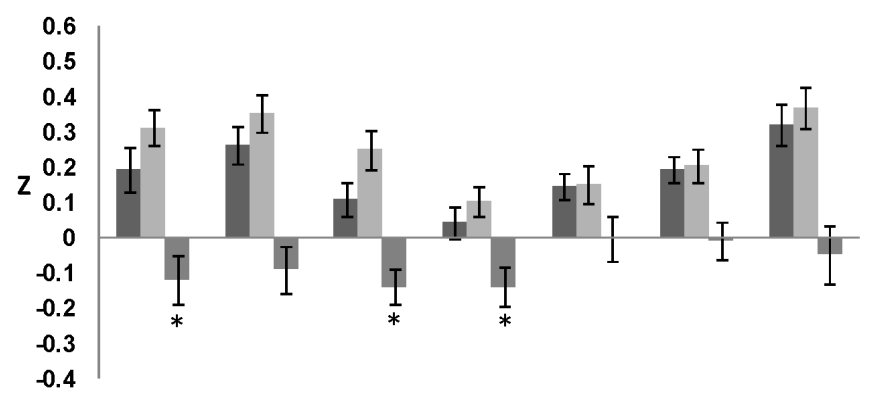

F4-P4

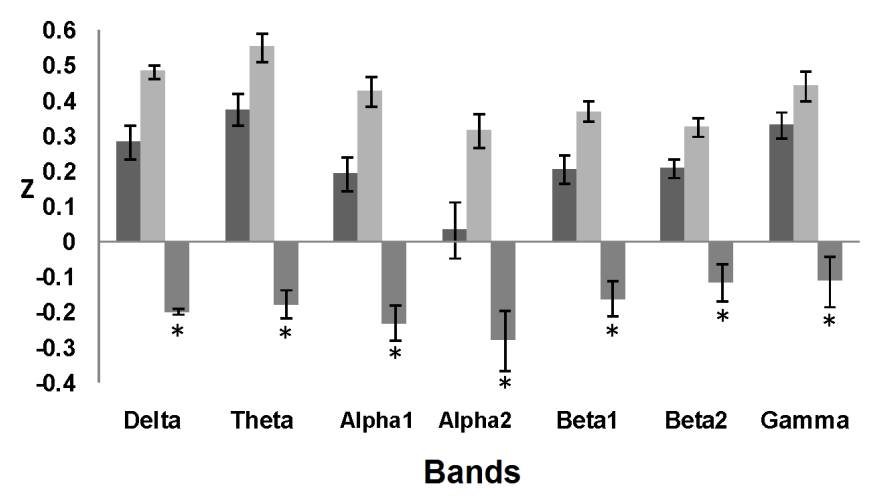

Figure 3. Intrahemispheric correlation converted to $\mathrm{Z}$ values (mean \pm 2 standard error) in the maintenance phase in the control and post-traumatic stress disorder (PTSD) groups, as well as the mean of differences between groups (MD \pm 1.96 S.E.). ${ }^{*} p<0.0005$.

\subsubsection{Recovery phase}

PTSD group presented higher intra-r than control group between the left frontal areas (F3-F7) and bilaterally between the frontal-temporal (F3-T3, F3-T5, F4-T6) and frontal-parietal (F3-P3, F4-P4) regions in the bands listed in Table 3 (Figure 5). As can be seen in Table 3, after Bonferroni correction the comparisons that did not reach the level of significance were: F3-F7 in alpha2, F3-T3 in beta2, F3-T5 in alpha1 and beta2, and F4-T6 in alpha2. There were no significant differences among type of stimulus or interactions among variables.

PTSD group showed higher correlation between the inferior frontal regions (F7-F8) in gamma, between the anterior temporal areas (T3-T4) in almost all bands (except 


\section{F7-F8}

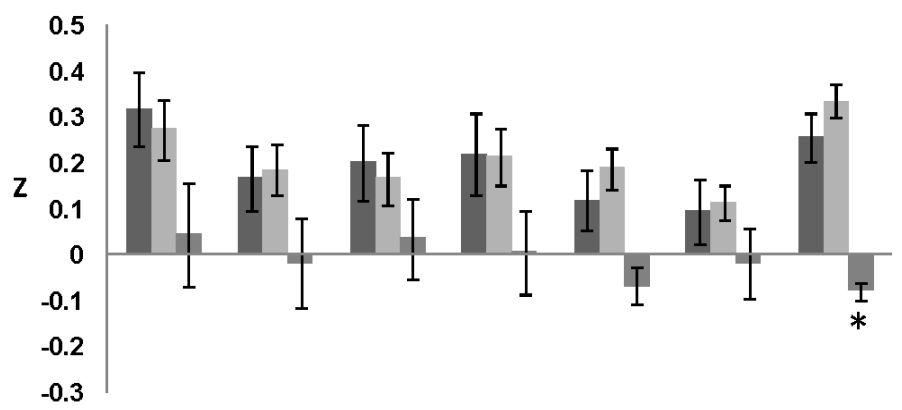

T3-T4

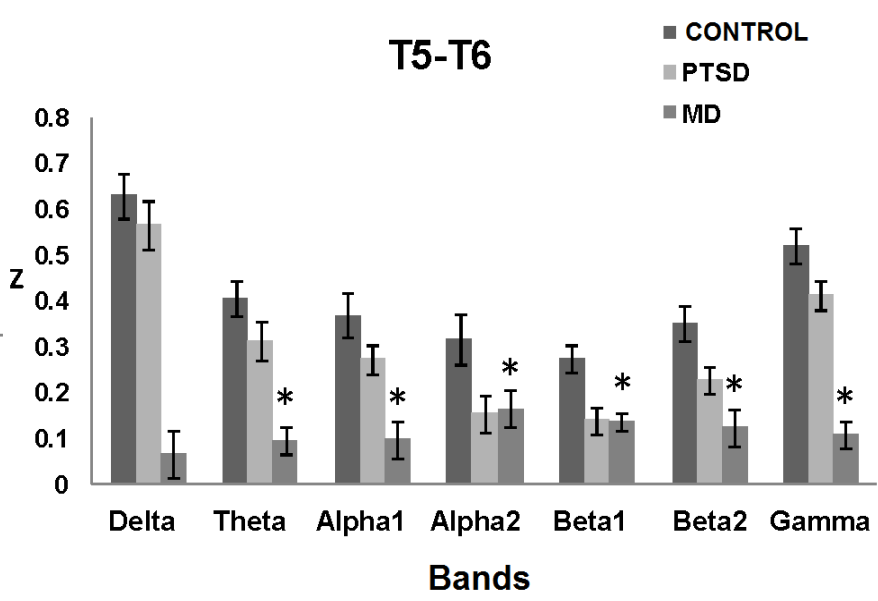

Figure 4. Interhemispheric correlation converted to $\mathrm{Z}$ values (mean \pm 2 standard error) in the maintenance phase in the control and post-traumatic stress disorder (PTSD) groups, as well as the mean of differences between groups $\left(\mathrm{MD} \pm 1.96 \mathrm{~S} . \mathrm{E}\right.$.). ${ }^{\star} \mathrm{p}<0.0005$.

alpha1), and between the parietal regions in theta (Figure 6, Table 3). In contrast, this group had lower inter-r than control group between the posterior temporal regions (T5-T6) in all bands (Figure 6, Table 3). After Bonferroni correction, the comparisons made at F7-F8 in gamma, T3-T4 in delta, alpha2, beta1 and beta2, and T5-T6 in delta did not reach the level of significance. There were no significant differences among type of stimulus or any interactions among variables.

\section{Discussion}

As we hypothesized, the study showed that PTSD group had a lower performance than control group while observing happy faces with higher intrahemispheric correlations among frontal and posterior cortical regions while maintaining and recovering information. However, there were no significant EEG differences according to the type of stimulus as we had expected.

\subsection{Behavioral Performance}

Compared to control, PTSD group presented lower performance on the working memory task when shown happy faces. This coincides with the findings of Cromheeke et al. [8] in adult women with a history of child sexual or physical abuse. In addition, PTSD had a similar performance while observing happy faces compared to the other stimuli, 


\section{F3-F7}

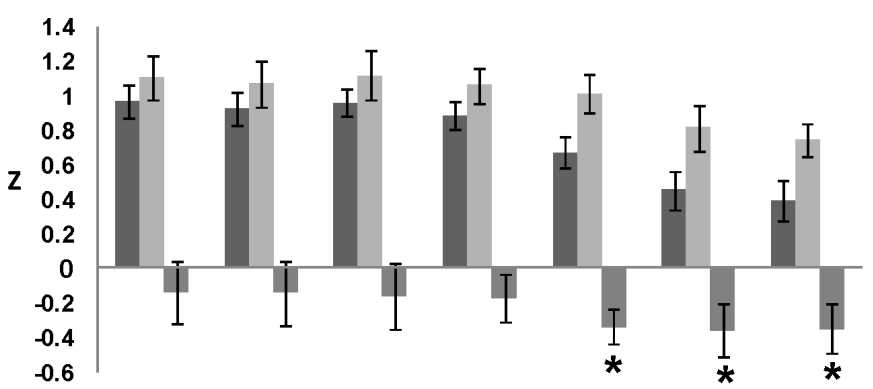

F3-T3

F4-T6
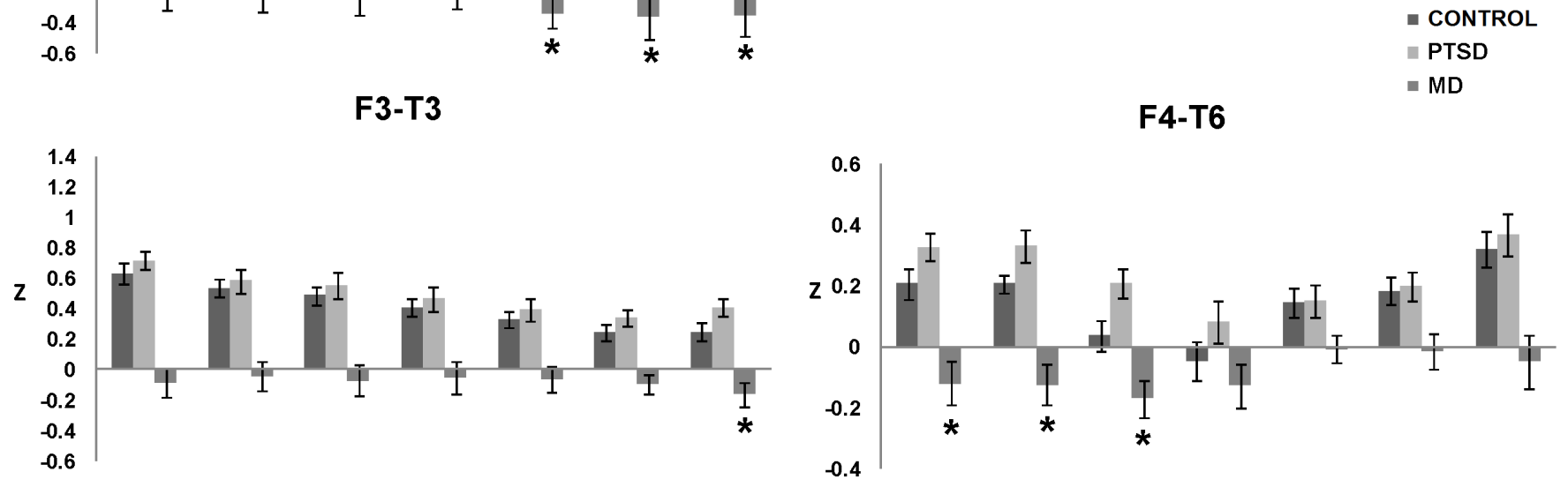

F3-P3
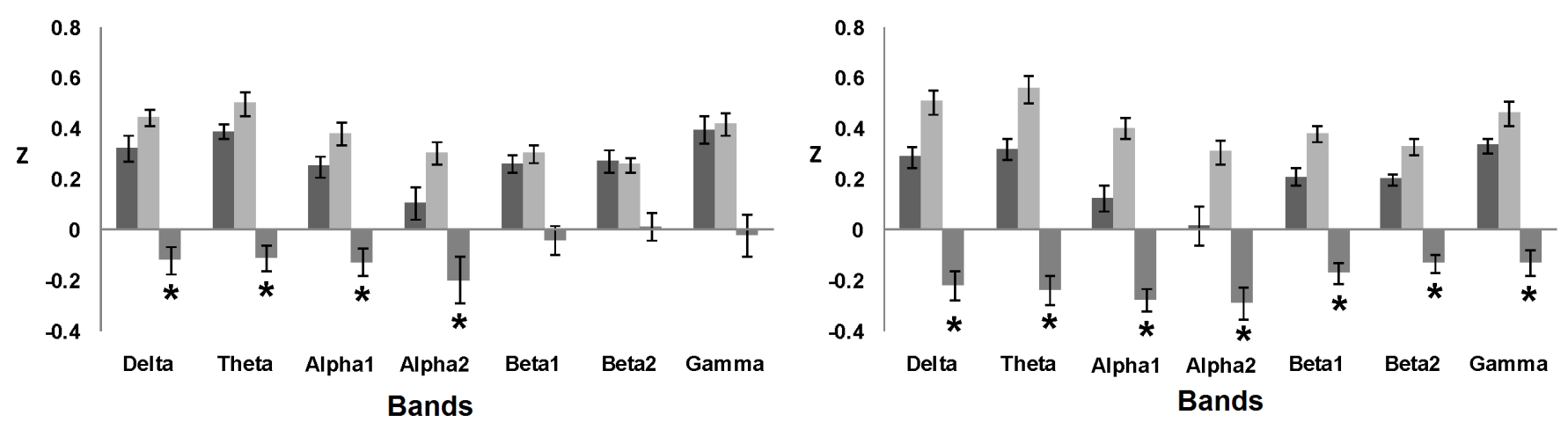

Figure 5. Intrahemispheric correlation converted to $\mathrm{Z}$ values (mean \pm 2 standard error) in the recovery phase in the control and post-traumatic stress disorder (PTSD) groups, as well as the mean of differences between groups (MD \pm 1.96 S.E.). ${ }^{\star}$ p $<0.0005$.

while control group exhibited a higher number of correct responses to the happy stimulus compared to the other expressions. In this regard, previous studies with healthy adults have observed that their performance on a working memory task with emotional stimuli is better when happy faces are shown [7], because this expression is easier to recognize than negative emotions [32]. Therefore, the brain resources involved in its processing are fewer than those needed to maintain and manipulate information in working memory. In contrast, faces with negative valence receive priority processing [33], such that fewer neural resources are available for other cognitive processes.

In contrast to controls, in the PTSD participants the happy face did not improve performance on the working memory task, probably because for them recognizing happy and negative faces entails a similar degree of difficulty, so processing required 
Table 3. ANOVAS of the inter and intrahemispheric EEG correlations during the recovery phase. $F$ values (free grades) and the significance ( $p$ ) of the pair of derivations and bands where there were significant differences between control and post-traumatic stress disorder groups.

\begin{tabular}{|c|c|c|c|c|}
\hline & Pairs of derivations & Bands & $\mathrm{F}_{(1,99)}$ & $\mathrm{p}<$ \\
\hline \multirow[t]{23}{*}{ Intrahemispheric correlation } & F3-F7 & Alpha2 & 6.97 & 0.009 \\
\hline & & Betal & 33.10 & $0^{*}$ \\
\hline & & Beta2 & 36.08 & $0^{*}$ \\
\hline & & Gamma & 37.74 & $0^{*}$ \\
\hline & F3-T3 & Beta2 & 10.21 & 0.002 \\
\hline & & Gamma & 25.56 & $0^{*}$ \\
\hline & F3-T5 & Alpha1 & 7.32 & 0.007 \\
\hline & & Beta2 & 7.32 & 0.007 \\
\hline & F4-T6 & Delta & 12.60 & $0^{*}$ \\
\hline & & Theta & 14.82 & $0^{*}$ \\
\hline & & Alpha1 & 30.56 & $0^{*}$ \\
\hline & & Alpha2 & 12.25 & 0.001 \\
\hline & F3-P3 & Delta & 15.06 & $0^{*}$ \\
\hline & & Theta & 15.06 & $0^{*}$ \\
\hline & & Alpha1 & 17.80 & $0^{*}$ \\
\hline & & Alpha2 & 24.96 & $0^{*}$ \\
\hline & $\mathrm{F} 4-\mathrm{P} 4$ & Delta & 52.20 & $0^{*}$ \\
\hline & & Theta & 62.32 & $0^{*}$ \\
\hline & & Alpha1 & 101.15 & $0^{*}$ \\
\hline & & Alpha2 & 72.66 & $0^{*}$ \\
\hline & & Beta1 & 48.33 & $0^{*}$ \\
\hline & & Beta2 & 44.59 & $0^{*}$ \\
\hline & & Gamma & 25.53 & $0^{*}$ \\
\hline \multirow[t]{15}{*}{ Interhemispheric correlation } & & Gamma & 7.18 & 0.008 \\
\hline & F7-F8 & Delta & 11.33 & 0.001 \\
\hline & T3-T4 & Theta & 15.95 & $0^{*}$ \\
\hline & & Alpha2 & 8.93 & 0.003 \\
\hline & & Betal & 9.42 & 0.003 \\
\hline & & Beta2 & 9.94 & 0.002 \\
\hline & & Gamma & 23.08 & $0^{*}$ \\
\hline & T5-T6 & Delta & 8.68 & 0.004 \\
\hline & & Theta & 12.97 & $0^{*}$ \\
\hline & & Alpha1 & 23.28 & $0^{*}$ \\
\hline & & Alpha2 & 37.93 & $0^{*}$ \\
\hline & & Beta 1 & 47.36 & $0^{*}$ \\
\hline & & Beta2 & 49.36 & $0^{*}$ \\
\hline & P3-P4 & Gamma & 16.19 & $0^{*}$ \\
\hline & & Theta & 7.28 & 0.008 \\
\hline
\end{tabular}

${ }^{*}$ Significant after Bonferroni correction $(\mathrm{p}<0.0005)$. 
T3-T4

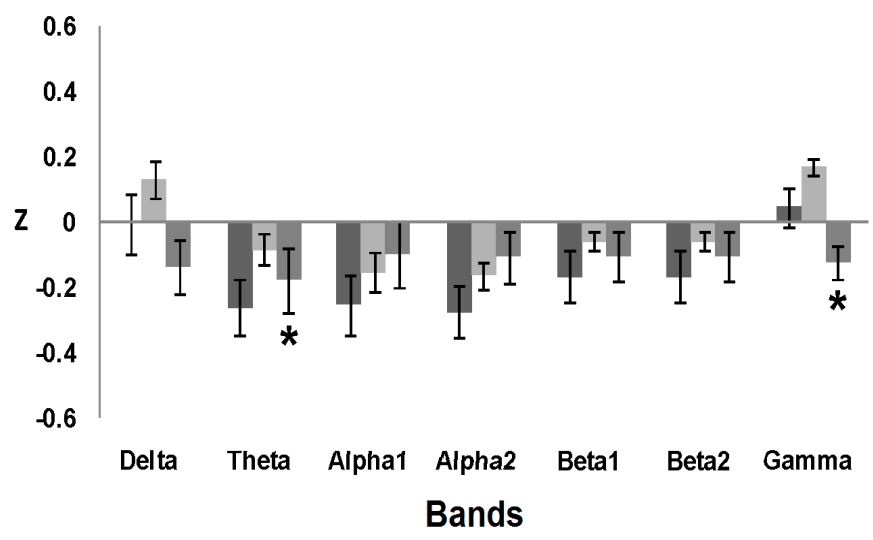

T5-T6

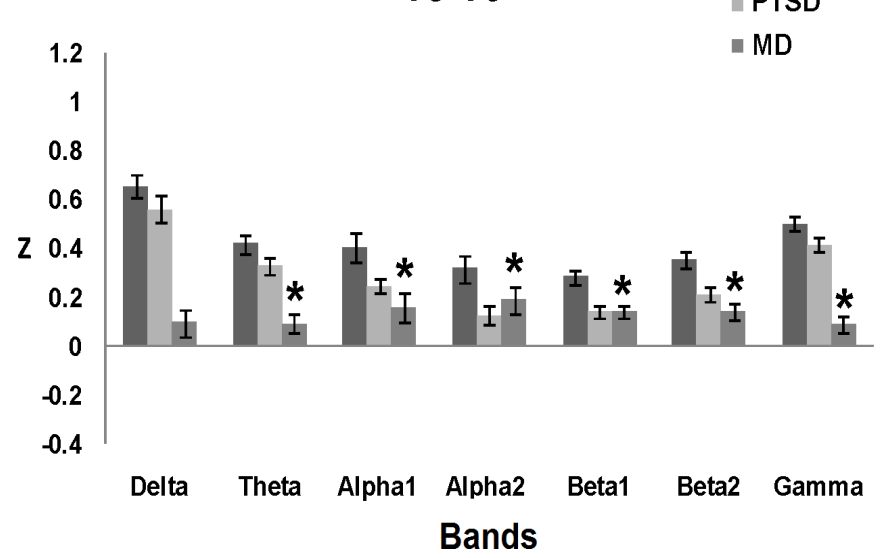

Figure 6. Interhemispheric correlation converted to $\mathrm{Z}$ values (mean \pm 2 standard error) in the recovery phase in the control and posttraumatic stress disorder (PTSD) groups, as well as the mean of differences between groups (MD \pm 1.96 S.E.). ${ }^{*} \mathrm{p}<0.0005$.

the same neural resources as those involved in working memory. This possibility should be considered despite the fact that on the pairing task the PTSD participants had-similar to controls-better performance with the happy faces than the other expressions, since this task had a low level of difficulty.

With respect to emotional recognition, previous reports have demonstrated that neglected children have difficulty in recognizing all emotions [3] and that incest survivors develop in environments where they have little opportunity to learn to correctly recognize emotions since their relations with both parents are inadequate [34] and there is a deficient communication between the non-offender mother and the abused son or daughter [35].

Another possible explanation of these results is the reduced reward sensitivity found early in individuals with a history of abuse [36], who may also fail to elevate their inhibitory control performance [37]. Thus, a question for future work concerns the implications of the reduced processing of positive emotions through cognitive and emotion control after experiencing early stress.

\subsection{EEG Correlation}

Several studies with working memory tasks have reported that there is an increased synchronization among prefrontal cortex and posterior cortical areas (parietal and temporal) in the alpha [19] and gamma bands [38] during information maintenance, as well as in theta and alpha [19] during manipulation and recovery. Moreover, this increase in theta shows lateralization, as it is greater in the left hemisphere for verbal tasks and in the right one for visual tasks [18].

We expected that when compared to control the PTSD group would have a lower intrahemispheric correlation among prefrontal and temporal/parietal regions while observing happy faces, in the alpha and gamma bands during the maintenance phase, and in the theta band during recovery. We expected these relations because the dorsolateral prefrontal cortex is implicated in attentional control [20], while the parietal and 
temporal lobes are involved in storing visual stimuli and processing emotional facial expressions [39] [40].

In contrast, our study showed that PTSD group presented a higher correlation between frontal and posterior regions, though this involved more frequency bands and did not circumscribe the right hemisphere as is expected on a visual task of this kind. In addition, this group showed higher interhemispheric synchronization in the frontal and parietal lobes in the gamma band. The latter findings indicate that PTSD group needed to utilize both hemispheres to perform the visual working memory task.

This higher functional coupling could be explained in two ways: a) PTSD made a greater cognitive effort during the working memory task; or, b) this group has lower cortical differentiation. These suggestions require some elaboration.

Regarding the first explanation, some studies have reported that anxious patients, or subjects under psychosocial stress, have lower performance on working memory tasks [41] [42], suggesting that such tasks demand greater effort. Since subjects with PTSD suffer from an anxiety disorder, it may be that the task was difficult for them, especially because it included emotional stimuli as analyzed in the preceding paragraphs.

In the EEG recordings taken during the working memory task, the frontal-parietal synchronization in theta increased with the degree of difficulty [43]. Similarly, in fMRI studies (i.e., functional magnetic resonance imaging), the functional connectivity among dorsolateral prefrontal and inferior parietal regions is greater as the memory load increases [44].

Considering the above evidence, it is likely that our PTSD group had to recruit more brain areas to perform the working memory task. A similar phenomenon has been observed in patients with mild cognitive impairment who, though presenting similar performance on working memory tasks to subjects without this condition, show higher inter-and intrahemispheric coherence in the alpha1 and alpha2 bands. This increase in coherence has been interpreted as reflecting the recruitment of additional brain areas to compensate for neurocognitive deficits [45].

PTSD also showed a higher left intrafrontal correlation (F3-F7) in the gamma band, indicating a synchronization between the dorsolateral and medial lateral prefrontal areas [46] that are responsible, respectively, for manipulating and monitoring information in working memory, and for making judgments about encoding and retrieving information stored in posterior regions [47]. The gamma band is involved in both the perceptual processing and maintenance of multiple elements in working memory, and increases linearly with task load and complexity [38].

The second explanation of the higher intrahemispheric correlation in PTSD is the presence of a lower cortical specialization with respect to control group, particularly in the systems involved in working memory. Similar to our study, Ito et al. [16] and Miskovic et al. [17] found an increased intrahemispheric functional coupling at rest. But those researchers only analyzed alpha band coherence, and the increased functional connectivity was found only in the left hemisphere. We consider that the increased correlation in PTSD could involve, as those authors suggest, lower brain differentiation. 
In this regard, it has been reported that in normal development there is a decrease in EEG coherence among cortical areas separated by a long distance $(\geq 18 \mathrm{~cm})$ [40], a phenomena related to an optimal organization of cortical networks. Also, the decrease in EEG coherence predicts higher intelligence [48].

It has been suggested that this lower cortical differentiation might be caused by altered patterns of cortical development due to the activation of monoamines and cortisol hypersecretion that affect cell migration, glial mitosis and myelination [49]. However, if PTSD had lower cortical differentiation, then the higher intrahemispheric correlation should also occur at rest and would constitute a structural feature of this group. Although we found that PTSD had higher frontal-parietal correlations than control group, these comparisons did not reach significance after strict Bonferroni correction. For this reason, future research must explore EEG correlations at rest in a large sample of participants with the same characteristics as those evaluated in this study.

Another interesting finding of this research was that PTSD group presented a reduced interhermispheric correlation between posterior temporal areas during the maintenance and recovery phases. This result is consistent with previous work [16] that found a higher hemispheric asymmetry among central, temporal and parietal areas in children while at rest who had suffered severe sexual or physical abuse. This result could be explained in part by the reduction of the medial area of the corpus callosum (IV), as has been observed in women who suffered child sexual abuse [50]. Together with the anterior commissure, this area connects to the superior and inferior temporal areas [51] [52] of both hemispheres.

While in the anterior temporal areas PTSD also had a lower interhemispheric correlation in the maintenance phase, during recovery it showed a greater correlation, so these changes cannot be attributed to the reduced volume of the tracts that connect the left and right anterior temporal regions. Also, the T3 and T4 derivations were placed in the left and right medial temporal gyrus ( $\mathrm{AB} 22$ ) [53] and so are connected only by the anterior commissure [52], and there are no reports of changes in this tract in victims of child abuse. This finding could indicate that the PTSD and control groups make different use of the anterior temporal areas during working memory tasks; that is, while control group requires synchronous recruitment of the anterior temporal areas of both hemispheres during information maintenance, PTSD performs this during recovery. In this regard, fMRI recorded in healthy adults during a working memory task involving facial stimuli have shown a bilateral activation of the medial and inferior temporal regions during information encoding, maintenance and retrieval [54].

Some limitations of the present study should be mentioned. The first is the small sample assessed due to the difficulty of finding participants who met the strict inclusion criteria. Although we screened girls from six foster homes in the state of Jalisco, Mexico, we were unable to obtain a larger sample because many potential subjects had low IQs, were in a school grade below their age, or had a personal or maternal history of drug use.

Second, it was impossible to separate and distinguish the impacts of PTSD and child sexual abuse because we could not gather a sample of participants with child sexual 
abuse who did not suffer PTSD as well. The high incidence of PTSD in institutionalized child sexual abuse survivors is a topic that needs to be analyzed in future research.

Finally, the findings of the present study may only apply to specific populations of children, as all our subjects came from families of low socioeconomic status recruited through foster homes. This method has the advantage of allowing verification of maltreatment, but it may introduce other kinds of stressors that can affect EEG activity [55] [56]. To identify the effects of child sexual abuse more precisely, a non-institutionalized control group without maltreatment and PTSD would be a valuable complement to an institutionalized control group in future work.

\subsection{Conclusions}

We believe that the information provided by this study will allow for a better understanding of the impact of early stressful events on the development of connectivity among the cortical structures that underlie working memory.

\section{Acknowledgements}

This work was supported by the CONAYCT under Grant CB/2012/180981. We thank Dr. Miguel Angel Guevara for his advice in the analysis of EEG signals. We also thank the institutions that kindly contributed to our research: Hogar Cabañas, Casa Hogar Florecitas del Carmen, Casa Hogar Kamami, Casa Hogar Ma. Teresa and Colegio de Especialidades Avanzadas en Sexualidad y Salud, A.C.

\section{References}

[1] Teicher, M.H., Andersen, S.L., Polcari, A., Anderson, C.M., Navalta, C.P. and Kim, D.M. (2003) The Neurobiological Consequences of Early Stress and Childhood Maltreatment. Neuroscience and Biobehavioral Reviews, 27, 33-44. http://dx.doi.org/10.1016/S0149-7634(03)00007-1

[2] Bagley, C. (1992) Characteristics of 60 Children and Adolescents with a History of Sexual asSault against Others: Evidence from a Comparative Study. The Journal of Forensic Psychiatry, 3, 299-309. http://dx.doi.org/10.1016/S0149-7634(03)00007-1

[3] Pollak, S.D., Cicchetti, D., Hornung, K. and Reed, A. (2000) Recognizing Emotion in Faces: Developmental Effects of Child Abuse and Neglect. Developmental Psychology, 36, 679688. http://dx.doi.org/10.1037/0012-1649.36.5.679

[4] Pollak, S.D., Klorman, R., Thatcher, J.E. and Cicchetti, D. (2001) P3b Reflects Maltreated Children's Reactions to Facial Displays of Emotion. Psychophysiology, 38, 267-274. http://dx.doi.org/10.1111/1469-8986.3820267

[5] Masten, C.L., Guyer, A.E., Hodgdon, H.B., McClure, E.B., Charney, D.S., Ernst, M., Kaufman, J., Pine, D.S. and Monk, C.S. (2008) Recognition of Facial Emotions among Maltreated Children with High Rates of Post-Traumatic Stress Disorder. Child Abuse \& Neglect, 32, 139-153. http://dx.doi.org/10.1016/j.chiabu.2007.09.006

[6] DePrince, A.P., Weinzierl, K.M. and Combs, M.D. (2009) Executive Function Performance and Trauma Exposure in a Community Sample of Children. Child Abuse \& Neglect, 33, 353-361. http://dx.doi.org/10.1016/j.chiabu.2008.08.002

[7] González-Garrido, A., Gómez-Velázquez, F.R., Sequeira, H., Ramos-Loyo, J. and López- 
Franco, A. (2013) Gender Differences in Visuospatial Working Memory-Does Emotion Matter? International Journal of Psychological Studies, 5, 11-21.

http://dx.doi.org/10.5539/ijps.v5n1p11

[8] Cromheeke, S., Herpoel, L.A. and Mueller, S.C. (2014) Childhood Abuse Is Related to Working Memory Impairment for Positive Emotion in Female University Students. Child Maltreatment, 19, 38-48. http://dx.doi.org/10.1177/1077559513511522

[9] Heim, C., Newport, D.J., Mletzko, T., Miller, A.H. and Nemeroff, C.B. (2008) The Link between Childhood Trauma and Depression: Insights from HPA Axis Studies in Humans. Psychoneuroendocrinology, 33, 693-710. http://dx.doi.org/10.1016/j.psyneuen.2008.03.008

[10] Andersen, S.L., Tomada, A., Vincow, E.S., Valente, E., Polcari, A. and Teicher, M.H. (2008) Preliminary Evidence for Sensitive Periods in the Effect of Childhood Sexual Abuse on Regional Brain Development. Journal of Neuropsychiatry and Clinical Neurosciences, 20, 292-301. http://dx.doi.org/10.1176/jnp.2008.20.3.292

[11] Boussaoud, D. and Bremmer, F. (1999) Gaze Effects in the Cerebral Cortex: Reference Frames for Space Coding and Action. Experimental Brain Research, 128, 170-180. http://dx.doi.org/10.1007/s002210050832

[12] Dannlowski, U., Stuhrmann, A., Beutelmann, V., Zwanzger, P., Lenzen, T., Grotegerd, D., Domschke, K., Hohoff, C., Ohrmann, P., Bauer, J., et al. (2012) Limbic Scars: Long-Term Consequences of Childhood Maltreatment Revealed by Functional and Structural Magnetic Resonance Imaging. Biological Psychiatry, 71, 286-293. http://dx.doi.org/10.1016/j.biopsych.2011.10.021

[13] Alba, A., Marroquin, J.L., Pena, J., Harmony, T. and Gonzalez-Frankenberger, B. (2007) Exploration of Event-Induced EEG Phase Synchronization Patterns in Cognitive Tasks Using a Time-Frequency-Topography Visualization System. Journal of Neuroscience Methods, 161, 166-182. http://dx.doi.org/10.1016/j.jneumeth.2006.10.018

[14] Murias, M., Swanson, J.M. and Srinivasan, R. (2007) Functional Connectivity of Frontal Cortex in Healthy and ADHD Children Reflected in EEG Coherence. Cerebral Cortex, 17, 1788-1799. http://dx.doi.org/10.1093/cercor/bhl089

[15] Shaw, J.C. (1984) Correlation and Coherence Analysis of the EEG: A Selective Tutorial Review. International Journal of Psychophysiology, 1, 255-266. http://dx.doi.org/10.1016/0167-8760(84)90045-X

[16] Ito, Y., Teicher, M.H., Glod, C.A. and Ackerman, E. (1998) Preliminary Evidence for Aberrant Cortical Development in Abused Children: A Quantitative EEG Study. Journal of Neuropsychiatry and Clinical Neurosciences, 10, 298-307. http://dx.doi.org/10.1176/jnp.10.3.298

[17] Miskovic, V., Schmidt, L.A., Georgiades, K., Boyle, M. and Macmillan, H.L. (2010) Adolescent Females Exposed to Child Maltreatment Exhibit Atypical EEG Coherence and Psychiatric Impairment: Linking Early Adversity, the Brain, and Psychopathology. Development and Psychopathology, 22, 419-432. http://dx.doi.org/10.1017/S0954579410000155

[18] Sarnthein, J., Petsche, H., Rappelsberger, P., Shaw, G.L. and von Stein, A. (1998) Synchronization between Prefrontal and Posterior Association Cortex during Human Working Memory. Proceedings of the National Academy of Sciences of the United States of America, 95, 7092-7096. http://dx.doi.org/10.1073/pnas.95.12.7092

[19] Kawasaki, M., Kitajo, K. and Yamaguchi, Y. (2010) Dynamic Links between Theta Executive Functions and Alpha Storage Buffers in Auditory and Visual Working Memory. European Journal of Neuroscience, 31, 1683-1689.

http://dx.doi.org/10.1111/j.1460-9568.2010.07217.x 
[20] Sauseng, P., Hoppe, J., Klimesch, W., Gerloff, C. and Hummel, F.C. (2007) Dissociation of Sustained Attention from Central Executive Functions: Local Activity and Interregional Connectivity in the Theta range. European Journal of Neuroscience, 25, 587-593. http://dx.doi.org/10.1111/j.1460-9568.2006.05286.x

[21] Baddeley, A.D. (1999) Working Memory. Essentials of Human Memory. Psychology Press, East Sussex.

[22] Tomoda, A., Navalta, C.P., Polcari, A., Sadato, N. and Teicher, M.H. (2009) Childhood Sexual Abuse Is Associated with Reduced Gray Matter Volume in Visual Cortex of Young Women. Biological Psychiatry, 66, 642-648. http://dx.doi.org/10.1016/j.biopsych.2009.04.021

[23] Wechsler, D. (Ed.) (2007) Escala Wechsler de inteligencia para niños-IV. Manual Moderno, México.

[24] American Psychatric Association (2014) Manual Diagnóstico y Estadístico de los Trastornos Mentales DSM-5. 5th Edition, Editorial Médica Panamericana.

[25] Zolotor, A.J., Runyan, D.K., Dunne, M.P., Jain, D., Peturs, H.R., Ramirez, C., Volkova, E., Deb, S., Lidchi, V., Muhammad, T., et al. (2009) ISPCAN Child Abuse Screening Tool Children's Version (ICAST-C): Instrument Development and Multi-National Pilot Testing. Child Abuse \& Neglect, 33, 833-841. http://dx.doi.org/10.1016/j.chiabu.2009.09.004

[26] Bustos, P., Rincón, P. and Aedo, J. (2009) Validación preliminar de la Escala infantil de síntomas del trastorno de estrés postraumático (Child PTSD Symptom Scale, CPSS) en niños/as y adolescentes víctimas de violencia sexual. PSYKHE, 18, 113-126. http://dx.doi.org/10.4067/S0718-22282009000200008

[27] Kovacs, M. (2004) Inventario de depresión infantil (CDI). TEA Ediciones, España.

[28] Hagemann, D., Naumann, E. and Thayer, J.F. (2001) The Quest for the EEG Reference Revisited: A Glance from Brain Asymmetry Research. Psychophysiology, 38, 847-857. http://dx.doi.org/10.1111/1469-8986.3850847

[29] Guevara, M.A., Hernández-González, M. and Sanz-Martin, A. (2010) CHECASEN: Programa para revisar señales EEG fuera de línea. Revista Mexicana de Ingeniería Biomédica, 31, 135-141.

[30] Guevara, M.A. and Hernández-González, M. (2009) EEGmagic: Programa para analizar señales electroencefalográficas. Revista Mexicana de Ingeniería, 30, 41-53.

[31] Guevara, M.A. and Corsi-Cabrera, M. (1996) EEG Coherence or EEG Correlation? International Journal of Psychophysiology, 23, 145-153. http://dx.doi.org/10.1016/S0167-8760(96)00038-4

[32] Becker, D., Anderson, U., Mortensen, C., Neufeld, S. and Neel, R.S. (2011) The Face in the Crowd Effect Unconfounded Happy Faces, not Angry Faces, Are More Efficiently Detected in Single and Multiple-Target Visual Search Task. Journal of Experimental Psychology. General, 140, 637-659. http://dx.doi.org/10.1037/a0024060

[33] Whalen, P.J., Rauch, S.L., Etcoff, N.L., McInerney, S.C., Lee, M.B. and Jenike, M.A. (1998) Masked Presentations of Emotional Facial Expressions Modulate Amygdala Activity without Explicit Knowledge. Journal of Neuroscience, 18, 411-418.

[34] Madonna, P.G., Van Scoyk, S. and Jones, D.P. (1991) Family Interactions within Incest and Nonincest Families. American Journal of Psychiatry, 148, 46-49. http://dx.doi.org/10.1176/ajp.148.1.46

[35] Levang, C.A. (1989) Father-Daughter Incest Families: A Theoretical Perspective from Balance Theory and GST. Contemporary Family Therapy, 11, 28-44. http://dx.doi.org/10.1007/BF00892344 
[36] Guyer, A.E., Kaufman, J., Hodgdon, H.B., Masten, C.L., Jazbec, S., Pine, D.S. and Ernst, M. (2006) Behavioral Alterations in Reward System Function: The Role of Childhood Maltreatment and Psychopathology. Journal of the American Academy of Child \& Adolescent Psychiatry, 45, 1059-1067. http://dx.doi.org/10.1097/01.chi.0000227882.50404.11

[37] Mueller, S.C., Hardin, M.G., Korelitz, K., Daniele, T., Bemis, J., Dozier, M., Peloso, E., Maheu, F.S., Pine, D.S. and Ernst, M. (2012) Incentive Effect on Inhibitory Control in Adolescents with Early-Life Stress: An Antisaccade Study. Child Abuse \& Neglect, 36, 217 225. http://dx.doi.org/10.1016/j.chiabu.2011.10.010

[38] Howard, M.W., Rizzuto, D.S., Caplan, J.B., Madsen, J.R., Lisman, J., AschenbrennerScheibe, R., Schulze-Bonhage, A. and Kahana, M.J. (2003) Gamma Oscillations Correlate with Working Memory Load in Humans. Cerebral Cortex, 13, 1369-1374. http://dx.doi.org/10.1093/cercor/bhg084

[39] Holmes, M.D., Ojemann, G.A. and Letich, E. (1996) Neuronal Activity in Human Right Lateral Temporal Cortex Related to Visuospatial Memory and Perception. Brain Research, 711, 44-49. http://dx.doi.org/10.1016/0006-8993(95)01351-2

[40] Rolls, E.T. (1999) The Brain and Emotion. Oxford University Press, New York.

[41] Darke, S. (1988) Effects of Anxiety on Inferential Reasoning Task Performance. Journal of Personality and Social Psychology, 55, 499-505. http://dx.doi.org/10.1037/0022-3514.55.3.499

[42] Oei, N.Y., Veer, I.M., Wolf, O.T., Spinhoven, P., Rombouts, S.A. and Elzinga, B.M. (2012) Stress Shifts Brain Activation towards Ventral "Affective" Areas during Emotional Distraction. Social Cognitive and Affective Neuroscience, 7, 403-412. http://dx.doi.org/10.1093/scan/nsr024

[43] Sauseng, P., Klimesch, W., Schabus, M. and Doppelmayr, M. (2005) Fronto-Parietal EEG Coherence in Theta and Upper Alpha Reflect Central Executive Functions of Working Memory. International Journal of Psychophysiology, 57, 97-103. http://dx.doi.org/10.1016/j.ijpsycho.2005.03.018

[44] Newman, S.D., Just, M.A. and Carpenter, P.A. (2002) The Synchronization of the Human Cortical Working Memory Network. NeuroImage, 15, 810-822. http://dx.doi.org/10.1006/nimg.2001.0997

[45] Zheng, L.L., Jiang, Z.Y. and Yu, E.Y. (2007) Alpha Spectral Power and Coherence in the Patients with Mild Cognitive Impairment during a Three-Level Working Memory Task. Journal of Zheijang University Science B, 8, 584-592. http://dx.doi.org/10.1631/jzus.2007.B0584

[46] Blume, W.T., Buza, R.C. and Okazaki, H. (1974) Anatomic Correlates of the Ten-Twenty Electrode Placement System in Infants. Electroencephalography and Clinical Neurophysiology, 36, 303-307. http://dx.doi.org/10.1016/0013-4694(74)90172-2

[47] Petrides, M. (2005) Lateral Prefrontal Cortex: Architectonic and Functional Organization. Philosophical Transactions of the Royal Society B, 360, 781-795. http://dx.doi.org/10.1098/rstb.2005.1631

[48] Anokhin, A.P., Lutzenberger, W. and Birbaumer, N. (1999) Spatiotemporal Organization of Brain Dynamics and Intelligence: An EEG Study in Adolescents. International Journal of Psychophysiology, 33, 259-273. http://dx.doi.org/10.1016/S0167-8760(99)00064-1

[49] Teicher, M.H., Ito, Y., Glod, C.A. and Gelbard, H.A. (1996) Neurophysiological Mechanisms of Stress Response in Children. In: Pfeffer, C.R., Ed., Severe Stress and Mental Disturbances in Children, American Psychiatric Press, Washington DC, 59-84.

[50] Teicher, M.H., Dumont, N.L., Ito, Y., Vaituzis, C., Giedd, J.N. and Andersen, S.L. (2004) 
Childhood Neglect Is Associated with Reduced Corpus Callosum Area. Biological Psychiatry, 56, 80-85. http://dx.doi.org/10.1016/j.biopsych.2004.03.016

[51] Witelson, S.F. (1989) Hand and Sex Differences in the Isthmus and Genu of the Human Corpus Callosum. A Postmortem Morphological Study. Brain, 112, 799-835.

http://dx.doi.org/10.1093/brain/112.3.799

[52] Samuelson, K.W., Krueger, C.E., Burnett, C. and Wilson, C.K. (2010) Neuropsychological Functioning in Children with Posttraumatic Stress Disorder. Child Neuropsychology, 16, 119-133. http://dx.doi.org/10.1080/09297040903190782

[53] Towle, V.L., Bolanos, J., Suarez, D., Tan, K., Grzeszczuk, R., Levin, D.N., Cakmur, R., Frank, S.A. and Spire, J.P. (1993) The Spatial Location of EEG Electrodes: Locating the Best-Fitting Sphere Relative to Cortical Anatomy. Electroencephalography and Clinical Neurophysiology, 86, 1-6. http://dx.doi.org/10.1016/0013-4694(93)90061-Y

[54] Nichols, E.A., Kao, Y.C., Verfaellie, M. and Gabrieli, J.D. (2006) Working Memory and Long-Term Memory for Faces: Evidence from fMRI and Global Amnesia for inVolvement of the Medial Temporal Lobes. Hippocampus, 16, 604-616.

http://dx.doi.org/10.1002/hipo.20190

[55] Eluvathingal, T.J., Chugani, H.T., Behen, M.E., Juhasz, C., Muzik, O., Maqbool, M., Chugani, D.C. and Makki, M. (2006) Abnormal Brain Connectivity in Children after Early Severe Socioemotional Deprivation: A Diffusion Tensor Imaging Study. Pediatrics, 117, 2093-2100. http://dx.doi.org/10.1542/peds.2005-1727

[56] Marshall, P.J. and Fox, N.A. (2004) A Comparison of the Electroencephalogram between Institutionalized and Community Children in Romania. Journal of Cognitive Neuroscience, 16, 1327-1338. http://dx.doi.org/10.1162/0898929042304723

\section{Submit or recommend next manuscript to SCIRP and we will provide best service for you:}

Accepting pre-submission inquiries through Email, Facebook, LinkedIn, Twitter, etc.

A wide selection of journals (inclusive of 9 subjects, more than 200 journals)

Providing 24-hour high-quality service

User-friendly online submission system

Fair and swift peer-review system

Efficient typesetting and proofreading procedure

Display of the result of downloads and visits, as well as the number of cited articles

Maximum dissemination of your research work

Submit your manuscript at: http://papersubmission.scirp.org/

Or contact jbbs@scirp.org 